\title{
RBEP
}

\section{Filosofia, psicanálise e educação: o "mestre possível" de adolescentes}

Valeska Zanello

\section{Resumo}

O presente artigo tem como escopo pensar uma articulação entre o lugar apontado pela psicanálise como o do "mestre possível" de adolescentes e o papel do professor na comunidade de investigação, no projeto Filosofia na Escola. Segundo uma leitura psicanalítica contemporânea, este lugar é marcado por um discurso do mestre permeado pelo do analista, isto é, por uma disposição de um mestre "não-todo poderoso", sujeito a aberturas, incertezas e dúvidas, trespassado pelo não saber. Defendemos a idéia de que a metodologia trabalhada no projeto Filosofia na Escola, através da comunidade de investigação, pode ser um meio propício para possibilitar o desabrochar desta disposição.

Palavras-chave: educação; ensino de adolescentes; filosofia; psicanálise.

\section{Abstract \\ Philosophy, psychoanalysis and education: a chat about the adolescents "possible master"}

The present article aims at thinking an articulation between the place pointed out by psychoanalysis as of the "possible master" of teenagers and the role of the teacher in the community, in the project "Philosophy in the 
School". According to the contemporaneous psychoanalysis, this place is marked by a speech of the master surrounded by the one of the analyst, i.e., of a "not-so powerful" master, subject to openings, uncertainties and doubts, trespassed by "not knowing". We defend the idea that the methodology worked in the project "Philosophy in the School", through the community, can make possible the development of this disposition.

Keywords: education; teenagers education; philosophy; psychoanalysis.

\section{Introdução}

É famosa a máxima freudiana segundo a qual psicanalisar, governar e educar seriam tarefas impossíveis (Freud, 1937). Segundo Kupfer (2001), tal máxima deve ser compreendida de maneira contextual, isto é, no momento histórico na qual surgiu e segundo as concepções de educação então vigentes. Para a autora, a crítica de Freud se dirige à concepção humanista e iluminista da educação, aquela que pressupõe e acredita em um sujeito completamente consciente e volitivo.

Sendo o reconhecimento e a afirmação do inconsciente a maior contribuição teórica de Freud, não poderia ele deixar de desconfiar de um projeto no qual uma alma educada, adulta, tentaria encaminhar a criança segundo seus próprios princípios e da cultura a qual representa. Freud coloca aí a impossibilidade de controle do inconsciente do outro, como uma espécie de ruído a mediar a relação entre o professor e o aluno. Isto se daria, sobretudo, pelo acontecimento da transferência (Freud, 1912, 1915), fenômeno psíquico que faz a criança colocar o professor num lugar especial, repetição de um determinado protótipo infantil. ${ }^{1}$ A partir deste lugar, muitas vezes desconhecido pelo próprio professor, sua palavra lhe escapa, pois nem mesmo sabe que recorte de seu discurso a criança (ou o inconsciente da criança) faz, muito menos que sentidos adquire (Kupfer, 1989). O fenômeno da transferência é que torna possível, ou pelo menos atuante, a educação. O lugar ocupado pelo professor (ou dado ao professor pelo inconsciente do aluno) é o do ideal do eu. Freud toma a si mesmo como exemplo; em seu texto "Algumas reflexões sobre a psicologia escolar", ao escrever sobre seus antigos mestres, ele nos diz:

Minha emoção ao encontrar meu velho mestre-escola adverte-me de que, antes de tudo, devo admitir uma coisa: é difícil dizer se o que exerceu mais influência sobre nós e teve importância maior foi a nossa preocupação pelas ciências que nos eram ensinadas, ou pela personalidade de nossos mestres (Freud, 1914, p. 286).

Que personalidade é esta? Ou, formulando a pergunta de maneira diferente: que disposição subjetiva é esta do professor que permite ou impede que a educação ocorra e que é tão marcante na vida dos alunos?

Para Millot (2001), em sua obra clássica Freud antipedagogo, educar é justamente uma tarefa impossível em função do desejo que permeia a
Segundo Laplanche e Pontalis (1992), a transferência (Übertragung) designa em psicanálise uma repetição de protótipos infantis, vivida com um sentimento de atualidade acentuada. Isto é, o sujeito repete determinadas formas infantis de relação, com novos objetos. Discuto detalhadamente o caráter metafórico da transferência em meu artigo "Metáfora e transferência", Revista Psicologia: Reflexão e Crítica, UFRGS (no prelo) 
Filosofia, psicanálise e educação: o "mestre possível" de adolescentes disposição do professor. Este desejo é, segundo a autora, um desejo de poder. Assim, se por um lado o aluno coloca o professor no lugar do ideal do eu, este pode querer ocupar narcisicamente este lugar, que é, de modo geral, um engodo. Em outras palavras, o professor pode ocupar o lugar de Mestre, ${ }^{2}$ reforçando o recalque e abrindo pouco espaço para o próprio movimento desejante do aluno (Kupfer, 1989).

Ainda para Millot, seria impossível haver um casamento da educação com a psicanálise. Ambas possuiriam objetivos diferentes, como, por exemplo: a análise visaria liquidar a transferência, a educação, a utilizá-la; e ainda, a análise se basearia na ética da verdade, enquanto a educação se basearia na moralidade social. Sua visão da educação ou do processo educativo parece ter sido a mesma (clássica) de Freud. É ultrapassando esse sentido que uma releitura da educação a partir da psicanálise tem se efetivado.

Segundo Kupfer (2001, p. 31), podemos pensar numa educação analítica seguindo

[...] a sugestão de que um educador possa ser um "mestre não-todo", matizado em certa medida pela posição do analista -, dos quais resulta um trânsito entre posições que a formulação de Millot, orientada pelas discussões político-institucionais da época, não permite.

Foi nesta direção que Gutierra (2003) realizou uma interessante pesquisa de mestrado, publicada no livro Adolescência, psicanálise e educação - o mestre "possível" de adolescentes. Segundo a autora, faz-se mister perguntar pela posição subjetiva do mestre possível de adolescentes. Para Freud (1905), a adolescência é um momento orgânico que gera um efeito psíquico - a mudança física gera um excesso de libido, cuja carga potencializa lembranças infantis e exige um posicionamento no campo da sexualidade. Uma das principais tarefas, na adolescência, seria o abandono dos pais, percebidos agora com seus defeitos e limites (trabalho de desligamento das figuras parentais). O adolescente percebe, nesta etapa de sua vida, que a promessa de gozo futuro realizada no Édipo e na Castração era um engodo. Falando de modo simples, ele percebe claramente que não há realização nem satisfação absolutas, tais quais ele vivenciou no começo de sua vida psíquica. Ele percebe também que o Outro é castrado; isto é, ele desconfia de qualquer discurso que se coloque como o verdadeiro, o "todo certo e poderoso".

A transferência adquire aqui uma coloração especial: ela coloca em xeque o "suposto saber", o discurso do mestre, que se coloca como um todo, completo, sem lacunas e fissuras. O bom professor seria assim aquele que se coloca plenamente como mestre, mas um mestre "nãotodo": não se trata de questão metodológica, mas posição subjetiva. Marcado pela falta que lhe faz trabalhar para saber, o Mestre se posiciona como castrado, e permite o desejo de saber do aluno: "Para tanto é preciso estar na posição paradoxal de ser um sujeito em falta para que o desejo de saber do aluno possa circular e produzir seus efeitos" (Gutierra, 2003, p. 87). Trata-se de "abrir espaço para a fala e o saber do aluno". É aqui que vislumbramos, apesar de diferentes perspectivas teóricas, uma ponte com
${ }^{2}$ Destacamos que os termos utilizados por Kupfer, e por nós também adotados, pertencem à leitura de Freud efetuada por Lacan, como, por exemplo, em seu Seminário Encore. 
a posição subjetiva do professor, possibilitadora e mediadora da comunidade de investigação - método específico do projeto Filosofia na Escola.

Para fazermos esta ponte, abordaremos um pouco a história do projeto e sua metodologia, para tornar claro ao leitor o quanto fica em xeque, aí, a subjetividade do próprio professor.

\section{Filosofia na Escola}

O projeto Filosofia na Escola nasceu no ano de 1998, numa parceria da Faculdade de Educação da Universidade de Brasília com a Fundação Educacional do Distrito Federal. Baseado no programa de Mathew Lipman, filósofo americano que criou mundialmente, na década de 60, nos EUA, a Filosofia para Crianças ${ }^{3}$ (voltada para uma educação para o pensar), o projeto se desenvolveu de forma dissidente e criativa. Lipman, por exemplo, criou manuais-novelas a serem utilizados pelos professores, de acordo com a faixa etária das crianças envolvidas e das habilidades a serem idealmente trabalhadas; no projeto, levou-se em consideração a especificidade da cultura escolar atendida, bem como a necessidade do professor de criar ativamente seus próprios materiais. A descrição mais minuciosa das semelhanças, diferenças, bem como das dissidências em relação ao projeto lipmaniano, podem ser encontradas no livro A Filosofia na escola pública (Kohan et al., 1999). ${ }^{4}$ Façamos, no entanto, uma espécie de resumo das principais idéias.

Lipman teve como leitmotiv, para a criação do projeto, a dificuldade de raciocinar que encontrava em seus alunos, na universidade. Sua idéia, então, foi a de ensinar a melhor pensar em níveis mais fundamentais da educação, aproveitando-se da curiosidade infantil, casando filosofia e infância. Apesar de esse pressuposto permanecer no projeto Filosofia na Escola, levamos adiante, de forma ainda mais contundente, a idéia de que a transformação implicada no projeto não abarcava somente o pensar, mas também a própria disposição subjetiva das pessoas nele envolvidas. Grande parte dessa transformação se dava pela metodologia do próprio projeto e das habilidades requeridas e treinadas para tal participação. Essa metodologia era a comunidade de investigação.

A idéia de uma comunidade de investigação é do próprio Lipman. Nela, os alunos e o professor sentam em roda, tomando como mote um tema livre, escolhido pelo grupo, a partir do qual se deve realizar perguntas. Escolhe-se, então, uma pergunta como ponto de partida para o diálogo e a discussão. Algumas regras se fazem aí estruturadoras: a necessidade de ouvir o outro (e as mais diversas opiniões) e qualificar sua fala, a necessidade de bem argumentar e relacionar a própria fala com o debate, a capacidade de traduzir as palavras do outros, a capacidade de lidar com as diferenças e os diferentes (Kohan, 1999) - metodologia mantida no projeto. Jackson e Oho (1999, p. 29) afirmam acerca da comunidade de investigação:

Evidentemente, disposições físicas implicam mensagens. A sala de aula mais tradicional com a escrivaninha do professor na frente e os alunos

\footnotetext{
${ }^{3}$ O leitor interessado pode encontrar a história e a metodologia de Filosofia para Crianças na coleção "Filosofia na Escola", da Editora Vozes. Ater-nos-emos aqui somente ao braço dissidente que se instaurou em Brasília.

${ }^{4}$ A história do projeto, na escola em que trabalhei (Centro Agrourbano do Gama), encontrase aí descrita. Essa escola foi tomada como modelo de pesquisa, visto que, inicialmente (no primeiro ano), adotamos os manuais de Lipman. Já no segundo ano, fizemos importantes transformações no programa: a) do uso dos manuais à criação de novos materiais; b) do papel passivo dos professores em relação à aula dos monitores a um papel ativo; e c) do levantamento do tema a ser debatido feito pelos monitores e professores à escolha das próprias crianças. Ver
} Loyola e Porto (2000). 
Filosofia, psicanálise e educação: o "mestre possível" de adolescentes sentados em fileiras ordenadas voltados para o professor transmite certas mensagens relativas ao poder e à autoridade na sala. É recomendável sentar-se em círculo sempre que seja possível e apropriado. Esse arranjo físico acaba estimulando a colaboração entre as crianças, ajudaas a se concentrarem mais no tema e permite o pleno contato visual. $\mathrm{O}$ círculo simboliza também a unidade da comunidade. Juntos, sentados de tal forma, como co-indagadores, professores e crianças podem iniciar a sua aventura de perguntar-se e "esquadrinhar sob a superfície".

Na comunidade de investigação não há um fechamento do tema debatido. Por exemplo, numa aula sobre violência, não se chega necessariamente à conclusão de que ela é má e deve ser evitada. Discute-se, primeiramente, o que é a violência e a pluralidade de seus matizes conceituais. Nesse sentido, nem toda violência é má, e há que se definir de que tipo de violência se está tratando. Em outras palavras, há um alargamento do espectro conceitual não só do aluno, mas do próprio professor. Não havendo fechamentos, comumente moralizadores como é de praxe nas escolas, deixa-se em aberto a possibilidade de convivência com opiniões diferentes e divergentes; isto é, as pessoas envolvidas neste processo percebem que a sua opinião é apenas uma opinião possível, e que precisa ser justificada. Aparece aqui o conceito de falibilidade: "enquanto o que nos falta saber é ilimitado, o que sabemos é sempre incerto, frágil e limitado" (Kohan, 1998, p. 104).

Esta abertura, de modo geral, traz muita angústia ao corpo docente, acostumado a ter sua palavra investida como o dogma máximo da verdade. Isto leva o professor a uma maior humildade, não apenas epistemológica, mas em relação à própria capacidade de pensar dos alunos, pois não é infreqüente ele se surpreender com as perguntas e as falas que emergem na comunidade de investigação. Neste sentido, a própria concepção do que vem a ser a infância, a criança, bem como a adolescência e o adolescente, se modifica. Esta disposição é transferida para outras matérias, de modo que o próprio professor passa a ver os conteúdos como postos provisórios de saber, isto é, o saber não como uma posse, mas um caminho, uma investigação (Kohan, 1998).

Interessa-nos aqui, especificamente, enfatizarmos essa metodologia do projeto denominada de "comunidade de investigação" e sua influência transformadora na disposição subjetiva do professor. Em outro artigo, "Subjetividade e filosofia com crianças: um relato de experiência e reflexão" (Zanello, 2005), abordamos especificamente essa transformação. Trata-se de um deslocamento da posição de um saber instituído para um questionarse e uma busca constante de saber. No entanto, como apontamos então naquele texto, não basta ao professor "aplicar" uma aula de filosofia com crianças, é preciso que ele mesmo vivencie, juntamente com o resto do corpo docente, a própria comunidade de investigação. Dito de outra maneira, é preciso que ele se veja em xeque no que tange aos seus valores, crenças, preconceitos, opiniões, que elas se tornem visíveis, exigentes de uma justificativa racional e, sobretudo, que sejam percebidas, no próprio embate comum na discussão, como uma de muitas possibilidades. Em outras palavras, o que torna o professor preparado para a atitude necessária como mediador da comunidade de investigação com as crianças é que tenha sido 
"desconstruído" na vivência da própria comunidade de investigação da qual participou ao preparar sua aula. Essa desconstrução envolve um tipo de transformação subjetiva, que o faz se colocar numa atitude diferente com as próprias crianças e com as questões que delas emergem.

Mas qual é a relação dessa disposição com o nosso tema acerca do "mestre possível" de adolescentes?

\title{
Filosofia (na escola), psicanálise e educação, uma conversa acerca do "mestre possível" de adolescentes
}

\author{
Segundo Cerletti (2002, p. 13),
}

[...] filosofia e educação mantiveram (e mantêm) uma relação complexa. Para além da pertinência de ser ensinada formalmente, um dos aportes que a filosofia pode fazer sobre os diversos aspectos da educação é elucidar seus conceitos, revisar suas hipóteses ou repensar suas problematizações.

De acordo com o que apontamos, através de nossa experiência de trabalho no projeto Filosofia na Escola, poderíamos acrescentar também: um dos papéis do ensino de filosofia seria mexer na disposição subjetiva daquele que não se atém apenas ao conteúdo da filosofia, mas à própria atividade de filosofar. Isto depende, obviamente, não apenas do conceito de filosofia com o qual se comunga, mas também da metodologia de trabalho adotada para seu ensino. Acreditamos, neste sentido, ser extremamente necessário repensar o próprio modo de ensino da filosofia no ensino superior, sobretudo nos diversos cursos de licenciatura, aqueles que preparam futuros professores de adolescentes. Faz-se mister, além disso, apontar a necessidade de trabalho filosófico constante, na própria escola, com esses professores. Trata-se não apenas de qualificar o momento específico de desenvolvimento psíquico que a adolescência comporta (o que colocará em xeque, a todo momento, o saber do próprio professor e sua disposição subjetiva), mas de aproveitar mesmo esta característica, para uma transformação do espaço educativo.

É neste sentido que apontamos a necessidade de se criar um projeto de "Filosofia com Professores" (usando uma analogia do Filosofia com Crianças), isto é, de haver mais trabalho efetivo e atuante do filosofar na formação de professores (em geral) do ensino médio, desde sua formação na faculdade até uma formação continuada, presente no decorrer de sua atividade de magistério, já nas escolas de ensino médio. A comunidade de investigação seria aqui não apenas desejável, mas extremamente necessária, visto que é profícua no sentido de permitir o desabrochar da disposição subjetiva necessária para o trabalho com adolescentes. Se o bom professor seria, como aponta Gutierra (2003), aquele que se coloca plenamente como mestre, mas um "mestre nãotodo", acreditamos que a própria metodologia da comunidade de investigação, desde que vivenciada pelos professores, pode ser facilitadora dessa disposição subjetiva. Trata-se, como já foi sublinhado, de uma abertura para a fala e o saber do aluno, só possíveis quando o professor se desinveste deste 
lugar de saber total. Assim, se a educação é impossível (no sentido da desconfiança freudiana no que tange ao controle do inconsciente do aluno), trata-se de torná-la pensável e, dentro desse limite, exeqüível e até emancipadora. É neste lugar marcado pelo não-saber (sabendo) que pode nascer no professor uma espécie de saber-fazer tão importante para uma prática educativa marcadamente analítica, necessária na relação e no trabalho com adolescentes.

\section{Referências bibliográficas}

CERLETTI, A. Filosofia/educação: os desafios políticos de uma relação complicada. In: KOHAN, W. O. (Org.). Ensino de filosofia: perspectivas. Belo Horizonte: Autêntica, 2002. p. 13-21.

FREUD, S. Três ensaios sobre a teoria da sexualidade [1905]. Rio de Janeiro: Imago, 1974. p. 123-252. (Edições Standard Brasileira, v. 7).

A dinâmica da transferência [1912]. Rio de Janeiro: Imago, 1974. p. 131-143. (Edições Standard Brasileira, v. 12).

. Observações sobre o amor transferencial (Novas recomendações sobre a técnica da psicanálise III) (1915 [1914]). Rio de Janeiro: Imago, 1974. p. 205-221. (Edições Standard Brasileira, v. 12).

. Algumas reflexões sobre a psicologia escolar (1914). Rio de Janeiro: Imago, 1974. p. 283-288. (Edições Standard Brasileira, v. 13). Análise terminável e interminável (1937). Rio de Janeiro:

Imago, 1974. (Edições Standard Brasileira, v. 23).

GUTIERRA, B. C. C. Adolescência, psicanálise e educação: o mestre "possível" de adolescentes. São Paulo: Avercamp, 2003.

JACKSON, T.; OHO, L. Preparando-se para filosofar. In: KOHAN, W. O.; WAKSMAN, V. (Org.). Filosofia para crianças na prática escolar. Petrópolis: Vozes, 1999. p. 23-83.

KOHAN, W. O. Fundamentos para compreender e pensar a tentativa de M. Lipman. In: KOHAN, W. O.; WUENSCH, A. M. (Org.). Filosofia para crianças: a tentativa pioneira de Mathew Lipman. Petrópolis: Vozes, 1998. p. 84-134.

Sugestões para implementar a filosofia em escolas. In: KOHAN, W. O.; WAKSMAN, V. (Org.). Filosofia para crianças na prática escolar. Petrópolis: Vozes, 1999. p. 85-112. 
KOHAN, W. O. et al. (Org.). Filosofia na escola pública. Petrópolis: Vozes, 2000. v. 4.

KUPFER, M. C. Freud e a educação: o mestre do impossível. São Paulo: Scipione, 1989.

Escuta, 2001.

Educação para o futuro: psicanálise e educação. São Paulo:

LAPLANCHE, Jean; PONTALIS, Jean-Bertrand. Vocabulário da

Psicanálise. 4. ed. São Paulo: Martins Fontes, 1992.

LOYOLA, V. M. Z.; PORTO, F. G. CEAG: a consolidação de uma nova proposta. In: KOHAN, W. O. et al. (Org.). Filosofia na escola pública. Petrópolis: Vozes, 2000. v. 4, p.149-179.

MILLOT, C. Freud antipedagogo. Rio de Janeiro: Zahar, 2001.

ZANELLO, V. Subjetividade e filosofia com crianças: um relato de experiência e reflexão. In: GONZALEZ-REY, Fernando (Org.). Complexidade, subjetividade e pesquisa em Psicologia. São Paulo: Thomson Learning, 2005. p. 381-396.

Valeska Zanello, doutora em Psicologia pela Universidade de Brasília (UnB), é professora do Instituto de Educação Superior de Brasília (Iesb)/ Brasília e das Faculdades Integradas Icesp/Brasília. Trabalha com formação de professores e foi monitora do projeto "Filosofia na Escola", desenvolvido pela UnB na Fundação Educacional do Distrito Federal.

valeskazanello@uol.com.br

Recebido em 12 de junho de 2006.

Aprovado em 19 de dezembro de 2006. 